\title{
INTERFACES CONTEMPORÂNEAS E SUA APLICABILIDADE NO AUXÍLIO DA ESCRITA BRAILE
}

\section{CONTEMPORARY INTERFACES AND ITS APPLICABILITY IN THE BRAILE WRITING}

\author{
Alexandre dos Santos Roque, M.Sc. (1) \\ Cristina Paludo Santos, M.Sc. (2) \\ Marcos Vinicius Heck, Bel. (3) \\ Cristiane Ellwanger, M.Sc. (4) \\ (1) Universidade Regional Integrada do Alto Uruguai e das Missões \\ e-mail: roque@san.uri.br \\ (2) Universidade Regional Integrada do Alto Uruguai e das Missões \\ e-mail:paludo@san.uri.br \\ (3) Universidade Regional Integrada do Alto Uruguai e das Missões \\ e-mail: marcosheck31@gmail.com \\ (4) Universidade Regional Integrada do Alto Uruguai e das Missões \\ e-mail: cristianeellwanger@gmail.com
}

Interface Vestível, Escrita Braile, Tecnologia Assistiva

Este artigo apresenta a Luva Braile - um dispositivo que faz uso das premissas da computação vestível para auxiliar o processo de escrita em braile. Para tanto utiliza-se a metodologia de realimentação táctil de força com estímulos vibratórios para auxiliar na digitação dos seis pontos específicos de um carácter braile.

\section{Interfaces, Braile Writing, Assistive Technology}

This paper presents the Braille Glove - a device that considers the premises of wearable computing to aid the process of writing in Braille. The methodology of tactile force feedback with vibration stimulus was used to aid in typing the six specific points of a braille character. 


\section{$16^{\circ}$ \\ ERGODESIGN USIHC CINAHPA}

\section{Introdução}

Vários recursos vêm sendo utilizados como mediadores do processo de ensino e de aprendizagem em ambientes inclusivos, dentre os quais destacam-se as tecnologias digitais. A evolução e popularização das tecnologias de informação e comunicação (TICs) impulsionou o surgimento de novas formas de interação do homem com sistemas computacionais e com elas emergem diferentes formas de relacionamento com o conhecimento e sua construção, assim como novas possibilidades pedagógicas [Araújo, Brito e Silva 2013].

No atual cenário, mais permeável à diversidade, diversas soluções computacionais têm sido utilizadas como recursos inclusivos, aprimorando a utilização dos materiais pedagógicos e acrescentando novos recursos no âmbito sócioeducacional. Este artigo alinha-se a esta perspectiva e apresenta uma solução tecnológica de auxílio à escrita Braille. O enfoque está no desenvolvimento de um sistema embarcado que faz uso de uma interface vestível para auxiliar pessoas com deficiência visual na digitação dos seis pontos específicos de um carácter braile.

Apesar do uso da computação vestível já ser investigado em diversas áreas do conhecimento, ainda há poucas discussões a respeito do seu potencial no contexto educacional. Os resultados das pesquisas realizadas por Moreira e Baranauskas (2015) quanto ao uso de tecnologias contemporâneas em ambientes educacionais inclusivos indicam que a maioria dos estudos é baseada em interface tangível ou interação por toque e que tecnologias vestíveis e interações gestuais ainda são pouco exploradas, sugerindo novos campos de pesquisa.

Sendo assim, este trabalho busca contribuir com um campo de investigação em aberto, com potencial de contribuição aos ambientes inclusivos. O foco é dado na tarefa de escrita em braile, dada a sua importância e as limitações existentes dos instrumentos de uso tradicional no ensino da escrita Braile [Silva et al 2014]. O reglete e a $16^{\circ}$ Ergodesign - Congresso Internacional de Ergonomia e Usabilidade de Interfaces Humano Tecnológica: Produto, Informações Ambientes Construídos e Transporte

$16^{\circ}$ USIHC - Congresso Internacional de Ergonomia e Usabilidade de Interfaces Humano Computador

CINAHPA | 2017 - Congresso Internacional de Ambientes Hipermídia para Aprendizagem. punção, por exemplo, exigem que o indivíduo escreva da direita para a esquerda, ao contrário da forma como ele lê, podendo gerar uma insatisfação do usuário na realização de produções textuais e, além disso, não provêm um feedback imediato das palavras escritas. Ainda há que se considerar os altos custos dos equipamentos, como o da máquina Perkins, que impede a sua aquisição em larga escala como uma forma alternativa de escrita.

Assume-se assim a seguinte questão-problema como mola propulsora para o desenvolvimento das pesquisas envolvidas nesta proposta: "Que ferramenta computacional pode ser desenvolvida para auxiliar no processo de escrita braile de forma a prover maior interatividade e independência ao deficiente visual?". Como hipótese de solução temse que um sistema implementado na forma de uma luva tátil e independente de computadores pode servir como suporte para o deficiente visual digitar textos, realizar correções em tempo real e em qualquer local e armazena-los para uso posterior. De acordo com Silva et al. (2014), dispositivos eletrônicos podem auxiliar e melhorar a confiabilidade no processo de escrita braile, bem como também, servir de ferramenta de ensino da linguagem braile.

Uma descrição mais detalhada da solução proposta é apresentada nas seções subsequentes. A seção 2 apresenta uma visão geral de algumas aplicações computacionais voltadas ao auxílio da escrita braile. A seção 3 descreve o processo de desenvolvimento do protótipo de uma luva para auxílio da escrita em braile, detalhando os componentes e a técnica de controle utilizada. A seção 4 descreve os resultados obtidos a partir de testes realizados com usuários. Por fim, a seção 5 apresenta as considerações finais e trabalhos futuros.

\section{Aplicações Computacionais para Auxílio da Escrita em Braile}

De acordo com pesquisas de Moreira e Baranauskas (2015), o desenvolvimento de aplicações computacionais que façam uso de tecnologias contemporânea tais como as vestíveis e tangíveis apresentam um índice relevante de 


\section{$16^{\circ}$ \\ ERGODESIGN USIHC CINAHPA}

crescimento a partir de 2012, sendo que a maior parte delas utilizam interface tangível, sendo que $30,43 \%$ com o toque como forma de interação e apenas uma ferramenta utiliza somente tecnologia vestível.

Dentre as aplicações incluídas nesse cenário destaca-se a solução proposta por Santos (2015) que considera a falta de acessibilidade dos dispositivos com ecrã tátil e propõe um par de luvas que permite ao utilizador invisual ler e escrever mensagens e ainda fazer gestos para realização de outras tarefas. A ênfase da proposta está em tornar os dispositivos móveis mais acessíveis a pessoas com deficiência visual, de forma que possam ser integrados no seu quotidiano.

Aquino (2015) também apresenta o aplicativo AbcNum Braile voltado para dispositivos móveis touchscreen e com a finalidade de auxiliar o processo de aprendizagem do alfabeto braile. $\mathrm{O}$ aplicativo faz uso de estímulos sonoros e tácteis e visa permitir que pessoas com baixa visão pratiquem, de forma dinâmica e interativa, atividades voltadas à leitura e escrita em braile.

Outro trabalho voltado ao contexto de aprendizagem do sistema braile é proposto por Santos (2016) que apresenta o Conversor Braile um dispositivo que permite a leitura tátil em braile. O sistema é composto por um software que implementa uma técnica para a representação das letras do alfabeto em braile e, também, por um hardware que contempla a plataforma de prototipagem Arduino e micro servos que foram a base para a concepção de uma célula braile. Segundo os autores o uso do sistema pode ser disponibilizado não apenas para as crianças cegas, mas também para professores e pais, para que possam ajudar seus alunos/filhos no processo de aprendizagem do sistema Braile.

O trabalho de Seim (2014) faz uso da abordagem de Passive Haptic Learning (PHL) para permitir que as pessoas possam aprender a "memória muscular" através de estímulos de vibração sem dedicar atenção ao estímulo. PHL pode ser facilitada por computadores portáteis, tais como $16^{\circ}$ Ergodesign - Congresso Internacional de Ergonomia e Usabilidade de Interfaces Humano Tecnológica: Produto, Informações Ambientes Construídos e Transporte

$16^{\circ}$ USIHC - Congresso Internacional de Ergonomia e Usabilidade de Interfaces Humano Computador

CINAHPA | 2017 - Congresso Internacional de Ambientes Hipermídia para Aprendizagem.

luvas com uma interface táctil incorporada. $\mathrm{O}$ projeto está em andamento e estudos estão sendo realizados com vistas a definição de um sistema para ensinar passivamente habilidades de digitação braile.

Embora já existam diversas pesquisas voltadas ao atendimento das necessidades de leitura e escrita de pessoas com deficiência visual, grande parte delas fazem uso de outras formas de interação e/ou outras tecnologias, o que as diferem da proposta apresentada neste artigo.

\section{Especificações do Dispositivo Proposto}

$\mathrm{O}$ artefato concebido constitui-se em um par de luvas que utiliza a metodologia de realimentação táctil de força com estímulos vibratórios para auxiliar na digitação dos seis pontos específicos de um carácter braile. A Figura 1 apresenta os 6 pontos que formam a cela Braille com exemplos de como são formados alguns caracteres e aponta quais são os dedos da luva correspondentes a cada ponto, fazendo analogia ao formato da cela braile.

Os números 1 a 6 representados na figura indicam as posições dos dedos utilizados para geração do caractere braile e são idênticas as posições das maquinas de escrever em braile para fácil a adaptação. Já as letras D e E simbolizam os dedos mínimos que são utilizados para execução das demais funções disponíveis, tais como informar ao sistema a correção dos dados inseridos; eliminar dados; inserir o caractere "espaço em branco" em um buffer e gravar os dados que estão no buffer em cartão de memória após verificar se os mesmos estão corretos.
Realização:






\section{$16^{\circ}$ \\ ERGODESIGN USIHC CINAHPA}

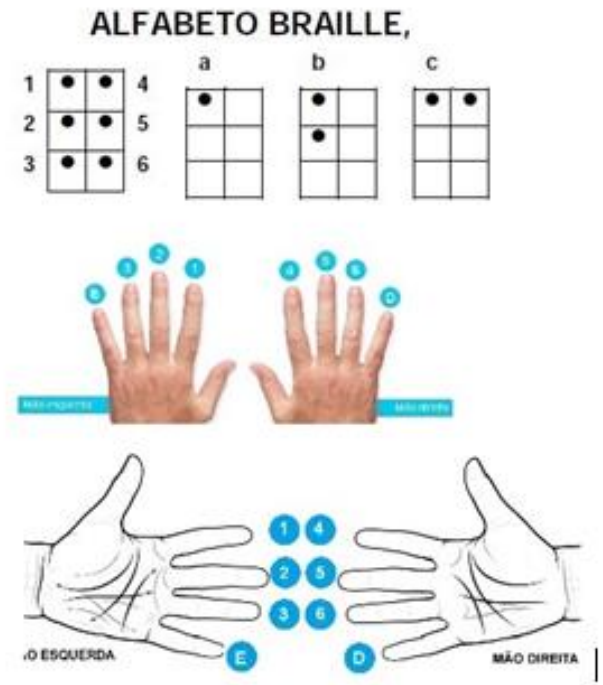

Figura 1. Caractere braile e sua representação no projeto da luva tátil

Para ativar uma função o usuário utiliza o botão presente no dedo mínimo da mãe direita (representado pela letra "D") juntamente com um dos botões existentes nos dedos numerados de 1 a 6. Para a confirmação de cada função o utilizador deve pressionar o botão presente no dedo mínimo da mão esquerda, representado pela letra E. A Tabela 1 apresenta as combinações possíveis que ativam as funções do sistema, bem como descreve a função e nomeias conforme apresentado no fluxograma da Figura 2.

Tabela 1. Funções do sistema

\begin{tabular}{|c|c|c|}
\hline $\begin{array}{c}\text { Combinação de } \\
\text { botões presentes } \\
\text { na luva tátil }\end{array}$ & Função Ativada & $\begin{array}{c}\text { Representação } \\
\text { no fluxograma }\end{array}$ \\
\hline $\mathrm{D}+1$ & $\begin{array}{c}\text { Provê o feedback } \\
\text { quanto aos dados } \\
\text { inseridos }\end{array}$ & $\mathrm{B} 1$ \\
\hline $\mathrm{D}+2$ & $\begin{array}{c}\text { Informa ao sistema } \\
\text { que os dados inseridos } \\
\text { estão corretos }\end{array}$ & $\mathrm{B} 2$ \\
\hline $\mathrm{D}+3$ & $\begin{array}{c}\text { Informa ao sistema } \\
\text { que os dados inseridos } \\
\text { estão incorretos e } \\
\text { devem ser eliminados }\end{array}$ & $\mathrm{B} 3$ \\
\hline $\mathrm{D}+4$ & $\begin{array}{c}\text { Insere o caractere } \\
\text { "espaço em branco" } \\
\text { em um buffer }\end{array}$ & $\mathrm{B} 4$ \\
\hline $\mathrm{D}+6$ & $\begin{array}{c}\text { Grava os dados que } \\
\text { estão no buffer em } \\
\text { cartão de memória }\end{array}$ & $\mathrm{B} 6$ \\
\hline
\end{tabular}

O fluxo de controle envolve 3 etapas. A etapa 1 compreende a realização da leitura de uma $16^{\circ}$ Ergodesign - Congresso Internacional de Ergonomia e Usabilidade de Interfaces Humano Tecnológica: Produto, Informações Ambientes Construídos e Transporte

$16^{\circ}$ USIHC - Congresso Internacional de Ergonomia e Usabilidade de Interfaces Humano Computador

CINAHPA | 2017 - Congresso Internacional de Ambientes Hipermídia para Aprendizagem.

combinação de pontos até que se confirme a inserção através do pressionamento do dedo mínimo esquerdo (“E”), responsável pelas confirmações tanto das inserções quanto das demais funções do sistema. Com a confirmação da etapa 1 o fluxo segue para a etapa 2 caso esteja sendo selecionada uma das funções apresentadas na tabela 1 ou para a etapa 3 caso esteja sendo realizada a inserção de dados. A Figura 2 apresenta um fluxograma que detalha o fluxo de controle.

Na etapa 2 verifica-se qual função foi selecionada e realizam-se os procedimentos necessários para execução da mesma, retornando o fluxo para o início da etapa 1 após a sua execução. Já na etapa 3 , que compreende a inserção de dados pelo usuário, é ativada a função responsável por interpretar a combinação dos botões pressionados e armazenar em buffer o caractere correspondente.

\subsection{Protótipo Desenvolvido}

Um protótipo foi desenvolvido para fins de validação e verificação da técnica de controle proposta. Para tanto utilizou-se a metodologia de prototipagem evolutiva com vistas a minimizar o tempo de desenvolvimento e refinamento do artefato.

Na ponta dos dedos foram acoplados botões do tipo Push Button para permitir a inserção de dados emulando uma máquina de escrever em braile. Para o usuário obter um feedback dos dados inseridos foi utilizado a técnica de sistemas de realimentação de informações táteis de força através de estimulo vibratório [Camargo 2008]. Para isto fez-se uso de micromotores vibracall, retirados de celulares antigos, acoplados nas falanges proximais dos dedos. Os motores foram instalados nessa posição a fim de que as vibrações fossem propagadas de forma que o utilizador consiga distingui-las. 

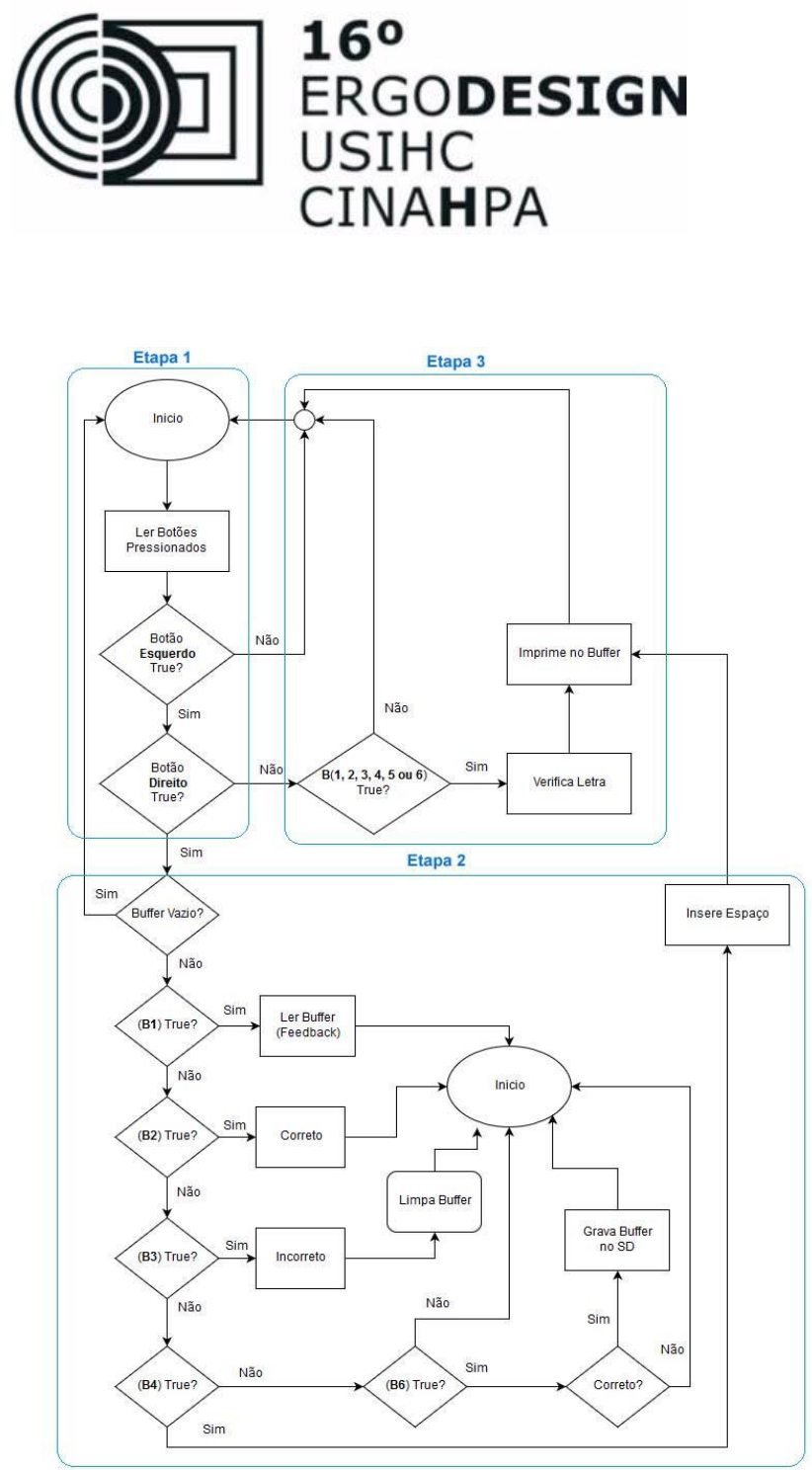

Figura 2. Fluxo de Controle

Para o controle do protótipo e interpretação dos dados utilizou-se o Arduino Uno (hardware de prototipagem rápida) e um módulo de cartão $\mathrm{SD}$ para armazenamento dos dados inseridos. $\mathrm{O}$ hardware de prototipagem rápida é responsável pelo controle dos botões posicionados na ponta dos dedos e pela verificação do feedback. Após a interpretação os dados podem ser armazenados em cartão de memória.

Desta forma, o processo de desenvolvimento envolveu as seguintes etapas:

(1) Montagem da luva - Nesta etapa foram acoplados na luva botões do tipo "Push Button" e um micromotor VibraCall. A Figura 3 apresenta registros desta etapa. $16^{\circ}$ Ergodesign - Congresso Internacional de Ergonomia e Usabilidade de Interfaces Humano Tecnológica: Produto, Informações Ambientes Construídos e Transporte

$16^{\circ}$ USIHC - Congresso Internacional de Ergonomia e Usabilidade de Interfaces Humano Computador

CINAHPA | 2017 - Congresso Internacional de Ambientes Hipermídia para Aprendizagem.
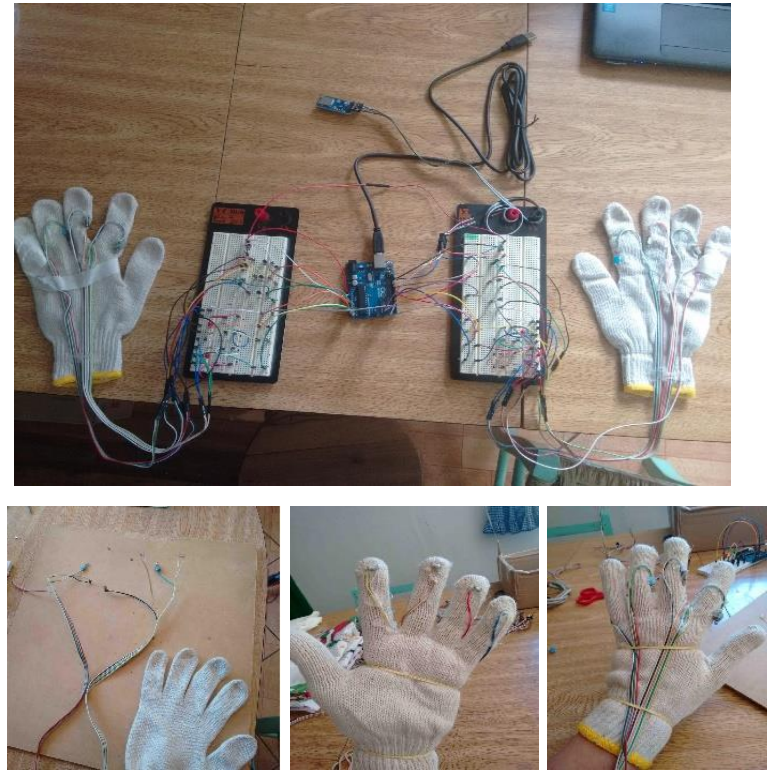

Figura 3. Montagem da luva

(2) Interligação no Hardware de Prototipagem Rápida Arduino- Após a montagem da luva foram realizadas as interligações dos botões e motores com o Arduino para controle do acionamento dos mesmos. As interconexões são apresentadas na Figura 4.

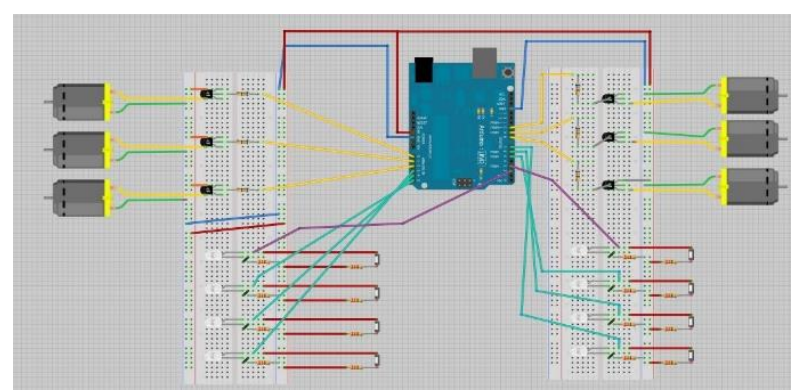

Figura 4. Conexões dos sensores e motores no Arduino

(3) Interligação do módulo de armazenamento de informações SD Card - Uma vez realizadas as ligações de controle, incluiu-se um módulo de armazenamento onde as informações inseridas pelo usuário são salvas em um cartão de memória do tipo "SD". A Figura 5 demonstra a conexão entre o arduino e o módulo de armazenamento. 
$16^{\circ}$ USIHC - Congresso Internacional de Ergonomia e Usabilidade de Interfaces Humano Computador

CINAHPA | 2017 - Congresso Internacional de Ambientes Hipermídia para Aprendizagem.

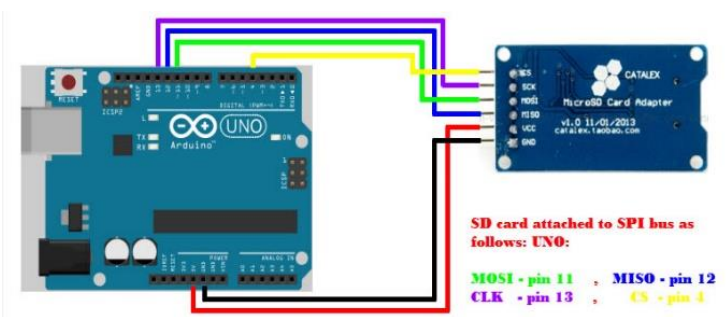

Figura 5. Conexão entre o Arduino e o Cartão de Memória

O uso deste tipo de módulo permite que futuramente as informações salvas possam ser utilizadas por softwares de leitura e também impressas. $\mathrm{O}$ encapsulamento utilizado também agrega confiabilidade ao sistema, pois trata-se de um módulo bastante difundido e amplamente utilizado em projetos de eletrônica. A Figura 6 apresenta o protótipo funcional da luva tátil.

Finalizada a etapa de prototipação e diante do estabelecimento da proposta destaca-se o papel fundamental e indispensável que usuários finais assumem na avaliação do dispositivo.

Figura 6. Protótipo Funcional da Luva Tátil

Considerar os aspectos de validabilidade, efetibilidade e usabilidade torna-se importante para realização de ajustes e, sobretudo, permitirá verificar a aplicabilidade desta forma de interação junto à comunidade invisual como ferramenta de apoio a escrita de textos. Neste sentido, uma série de testes práticos com usuários foi realizada para fins validação da arquitetura e do algoritmo de controle embarcado. A próxima seção detalha os testes e resultados obtidos.

\section{Resultados Obtidos}

O protótipo desenvolvido passou por testes com vistas a avaliar se o mesmo executa corretamente as funções para as quais foi projetado. Para fins de testes funcionais dois usuários que não possuem deficiência visual participaram do processo. Já, para testes que visam avaliar a aplicabilidade, efetibilidade e usabilidade contou-se com a participação de um usuário com deficiência visual total. A presença de usuários com e sem deficiência visual no processo avaliativo permite analisar como a interface proposta afeta distintos públicos e o quanto é viável o seu uso no desenvolvimento de tecnologias voltadas à comunidade invisual.

O processo de avaliação envolveu inicialmente uma explanação para os usuários participantes quanto a finalidade e funcionalidades do dispositivo. Para os usuários com capacidades visuais a explanação foi realizada por meio de diagramas, figuras e manual de uso e, para o usuário com deficiência visual, foi feita uma apresentação oral. Tendo em vista que o usuário com deficiência visual apresenta conhecimento e familiaridade no uso da máquina Perkins, não houveram problemas em relação ao entendimento do funcionamento das luvas, já que a forma de interação disponível na luva aproxima-se ao utilizado pela máquina de escrever em braile.

Foram definidos 3 testes envolvendo as seguintes palavras: luva braile (teste 1), auxilio a escrita (teste 2) e protótipo em laboratório (teste 3). Todas as palavras devem ser armazenadas em cartão de memória. Em cada teste foram considerados os parâmetros do tempo para realização e taxa de acertos na realização das tarefas. A partir destes parâmetros foi possível avaliar aspectos de usabilidade e o atendimento dos demais requisitos funcionais da aplicação. A Figura 7 apresenta os arquivos gerados para armazenamento do conteúdo inserido por cada um dos usuários.

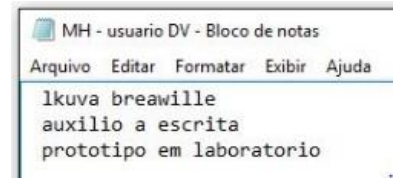

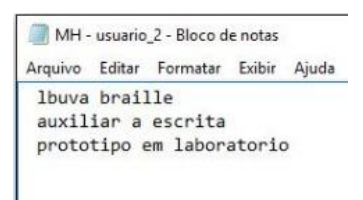

Figura 7. Arquivos gerados no cartão de memória na realização dos testes

Os resultados obtidos em relação ao tempo de execução e taxa de acertos em cada teste são apresentados nos gráficos da Figura 7.
Realização:
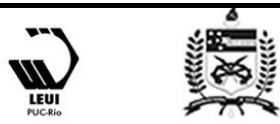


\section{$16^{\circ}$ \\ ERGODESIGN USIHC CINAHPA}


Figura 8. Resultados dos testes em relação ao tempo de execução e taxas de acerto

Em relação aos dados dos gráficos percebe-se que os usuários sem deficiência visual demandaram maior tempo para realização das atividades em comparação com o tempo de execução do invisual. Isto ocorreu tendo em vista que tais usuários por desconhecerem o sistema braile necessitavam realizar consultas sobre como representar cada caractere. A mesma situação ocorreu em relação a taxa de acertos. Assim, presume-se que as dificuldades encontradas estão relacionadas com a pouca familiaridade dos usuários com o sistema braile e não com questões de usabilidade no manuseio do dispositivo.

Além disso, o usuário invisual por possuir uma sensibilidade acentuada conseguiu perceber o feedback do dispositivo em relação as letras do texto inserido. $\mathrm{O}$ mesmo não ocorreu com os usuários sem deficiência que não conseguiram identificar os retornos vibratórios fornecidos pelo dispositivo, A Figura 9 apresenta registros fotográficos dos usuários durante a realização dos testes. $16^{\circ}$ Ergodesign - Congresso Internacional de Ergonomia e Usabilidade de Interfaces Humano Tecnológica: Produto, Informações Ambientes Construídos e Transporte

$16^{\circ}$ USIHC - Congresso Internacional de Ergonomia e Usabilidade de Interfaces Humano Computador

CINAHPA | 2017 - Congresso Internacional de Ambientes Hipermídia para Aprendizagem.

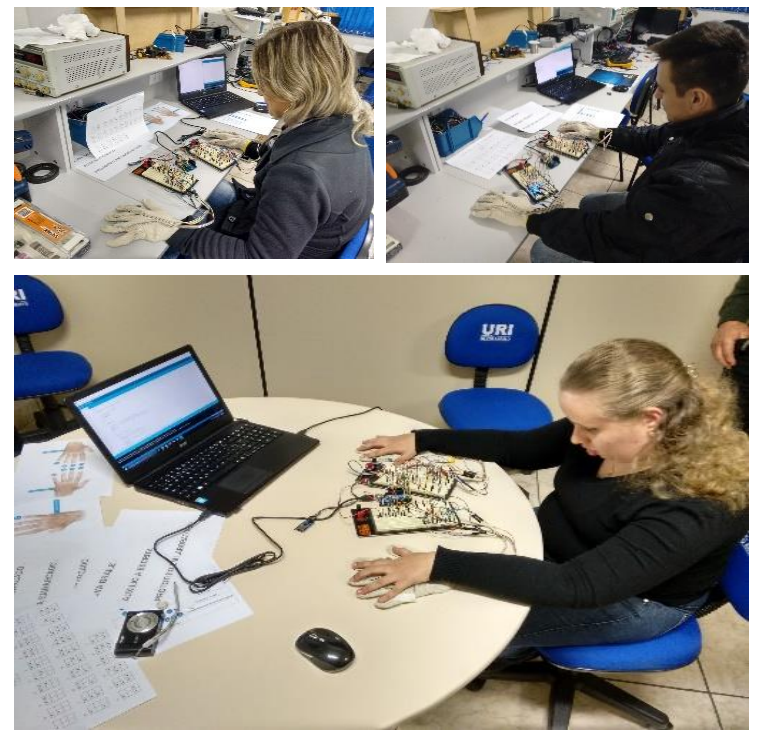

Novos testes deverão ser realizados envolvendo usuários com deficiência visual que não possuam habilidades no manuseio de máquinas de escrever em braile. A partir disso, será possível avaliar com maior precisão os aspectos de usabilidade empregados na interface do dispositivo proposto. Não obstante, destaca-se a importância dos resultados obtidos até o momento, pois consolidam a viabilidade da proposta, abrindo portas para futuros desenvolvimento relacionados a tecnologias assistivas e computação vestível para o público com deficiência visual.

\section{Considerações Finais e Trabalhos Futuros}

O desenvolvimento de novas tecnologias é impulsionado por necessidades muitas vezes criadas para as pessoas sem deficiência, as quais usam tecnologias e descobrem novas possibilidades a partir do seu uso. Quando se trata de pessoas com deficiência normalmente buscamse tecnologias que realizem tarefas simples do cotidiano destas pessoas, pois estas buscam a sua devida e merecida inclusão natural na sociedade. Neste sentido, o desenvolvimento de tecnologias alternativas, que permitam a inclusão de deficientes visuais na sociedade moderna é extremamente importante.

$\mathrm{O}$ artefato tecnológico proposto por meio de uma luva braile mostra que ainda existem muitas 


\section{$16^{\circ}$ \\ ERGODESIGN USIHC CINAHPA}

alternativas tecnológicas envolvendo mecanismos de hardware em conjunto com sistemas de informação embarcados. A metodologia aplicada baseada em realimentação táctil de força, que gera estímulos vibratórios mostrou-se satisfatória durante os testes realizados em laboratório e também com usuários. Os resultados do protótipo desenvolvido mostraram sucesso em mais de $80 \%$ dos testes realizados, destacando que após uma sequência de operações os usuários melhoraram seu desempenho mesmo aumentando a quantidade de caracteres a digitar. Este desempenho sugere que é possível a utilização de um dispositivo vestível no âmbito da comunidade invisual.

Tendo em vista a importância de artefatos que facilitem o processo de ensino e aprendizagem do sistema braile, o dispositivo proposto apresenta-se como uma alternativa no contexto educacional. Apesar dos resultados deste estudo demonstrarem a aplicabilidade da computação vestível no auxílio da escrita em braile acredita-se que é possível estender $o$ alcance desta tecnologia a outras aplicações que promovam contribuições no campo de ambientes educacionais inclusivos.

Por fim, com o crescimento exponencial do mercado de computação vestível e o esforço que a comunidade acadêmica tem dispendido no desenvolvimento de tecnologias assistivas, surgem diversas possibilidades e demandas de desenvolvimento tecnológico. Como sugestão de trabalhos futuros, pode-se ampliar este estudo para o desenvolvimento de outras aplicações voltadas ao público com deficiência visual ou para públicos com outros tipos de deficiência

\section{Referências Bibliográficas}

AQUINO, W., et al. "AbcNum Braille: Proposta de um Aplicativo para Auxiliar no Aprendizado do Alfabeto Braille para Pessoas com Baixa Visão." Anais do Simpósio Brasileiro de Informática na Educação (SBIE). Vol. 26. No. 1. 2015.

ARAÚJO, A. L. S. O, Brito R. R., Silva, A. P. (2013) "Softwares Para Educação Inclusiva: Uma Revisão Sistemática no Contexto de SBIE E WIE." In: Congresso Brasileiro de Informática na $16^{\circ}$ Ergodesign - Congresso Internacional de Ergonomia e Usabilidade de Interfaces Humano Tecnológica: Produto, Informações Ambientes Construídos e Transporte

$16^{\circ}$ USIHC - Congresso Internacional de Ergonomia e Usabilidade de Interfaces Humano Computador

CINAHPA | 2017 - Congresso Internacional de Ambientes Hipermídia para Aprendizagem.

Educação (CBIE), 507-15.

CAMARGO, D. R. Desenvolvimento do Protótipo de uma Prótese Antropomórfica para Membros Superiores. 186 f. 2008. Tese de Doutorado.

Dissertação (Mestrado)-Curso de Engenharia Elétrica, Escola de Engenharia de São Carlos da Universidade de São Paulo, São Carlos.

MOREIRA, Eliana; Baranauskas, M. Cecília. "Tecnologias tangíveis e vestíveis como recursos para ambiente inclusivo: uma revisão sistemática." In: Anais do Simpósio Brasileiro de Informática na Educação (SBIE), Vol. 26. No. 1. 2015.

SANTOS, Cristina Paludo; Roque, Alexandre dos Santos; Teixeira, Gustavo; Zago, Emmanuel. Conversor Braile: Um Aporte ao Processo de Alfabetização de Pessoas com Deficiência Visual. In: Anais do Seminário Nacional de Inclusão Digital. Passo Fundo: Ed. Universidade de Passo Fundo, 2016.

SANTOS, Fábio Alexandre Aleluia dos. Designing wearable interfaces for blind people. 2015. Tese de Doutorado.

SEIM, Caitlyn E., David Quigley, and Thad E. Starner. "Passive haptic learning of typing skills facilitated by wearable computers." $\mathrm{CHI}^{\prime} 14$

Extended Abstracts on Human Factors in Computing Systems. ACM, 2014.

SILVA, A. R. S., et al. "Especificação e desenvolvimento de um ambiente educativo móvel para a prática da escrita Braille." In Anais do Simpósio Brasileiro de Informática na Educação (SBIE), v. 25, n. 1. 2014. 